\title{
Opção decolonial e modos outros de conhecer na Educação (Matemática)
}

\author{
Carolina Tamayo ${ }^{1}$ \\ UFMG, Faculdade de Educação, \\ Departamento de Métodos e Técnicas de Ensino, Belo Horizonte, Minas Gerais, Brasil
}

Jackeline Rodrigues Mendes ${ }^{2}$

UNICAMP, Faculdade de Educação, Departamento de Ensino e Práticas Culturais, Campinas, São Paulo, Brasil

\begin{abstract}
Resumo
Neste artigo pretendemos trazer à discussão questões para pensar os efeitos de se assumir uma opção decolonial no campo da Educação Matemática, em particular na Etnomatemática. Essa noção tem inspiração na discussão de Walter Mignolo que entende a opção decolonial quando há um caminho de desprendimentos e aberturas no campo do pensamento crítico. Centraremos nosso olhar nos estudos sobre decolonialidade do saber e seus vínculos com a problematização empreendida no campo da Etnomatemática, no que diz respeito à narrativa universalizante da Matemática. Tal movimento de decolonização do pensamento e do saber é possível quando emergem outras formas de se desenhar o que se entende por conhecimento a partir de outras matrizes que não as colocadas pela colonialidade/modernidade. Assim, problematizamos o perigo das imagens naturalizadas sobre a Matemática como efeito da colonialidade do saber. Esse movimento pretende partir de um desvinculamento epistemológico dos fundamentos dos conceitos ocidentais e da acumulação de conhecimento, para aprender a desaprender. Concluímos que assumir uma atitude decolonial nos coloca numa posição de crítica contínua a todo processo de colonização epistêmica, para que não sejamos capturados pelas armadilhas da colonialidade/modernidade, armadilhas que mantém um único referencial epistêmico como válido para pensar as matemáticas, no plural.
\end{abstract}

Palavras-chave: Etnomatemática; Colonialidade; Relações Epistêmicas de Poder.

Submetido em: 16/06/2021 Aceito em: 18/08/2021 Publicado em: 03/09/2021

\footnotetext{
${ }^{1}$ Doutora em Educação pela Universidade Estadual de Campinas (Brasil). Professora do Programa de Pós-Graduação em Educação: Conhecimento e Inclusão Social da Universidade Federal de Minas Gerais (Brasil) e integrante do grupo de pesquisa interinstitucional inSURgir da mesma universidade. Integrante dos grupos de pesquisa "Phala: Educação, Linguagem e Práticas Educativas" (FE-UNICAMP) e do grupo "Matemática, Educación y Sociedad" da Universidad de Antioquia (Colômbia). Coordenadora para América do Sul da Red Internacional del Etnomatemática. E-mail: carolinatamayo@ufmg.br

${ }^{2}$ Doutora em Lingüística Aplicada pela Universidade Estadual de Campinas (Brasil). Professora da Faculdade de Educação da Universidade Estadual de Campinas e líder do grupo de pesquisa "Phala: Educação, Linguagem e Práticas Educativas" da mesma universidade. E-mail: jamendes@unicamp.br.
} 


\section{Opción decolonial y modos otros de conocer en la Educación (Matemática)}

\section{Resumen}

En este artículo pretendemos traer a discusión elementos para reflexionar sobre los efectos de asumir una opción decolonial en el campo de la Educación Matemática y, particularmente en Etnomatemática. Esta noción se inspira en la discusión de Walter Mignolo quien entiende la opción decolonial cuando hay un camino de desapego y aberturas en el campo del pensamiento crítico. Centraremos nuestra mirada en la decolonialidad del saber y sus vínculos con la problematización, emprendida en el campo de la Etnomatemática, con respecto a la narrativa universalizante de la Matemática. Tal movimiento de decolonización del pensamiento y del saber es posible cuando otras formas de comprensión emergen sobre el conocimiento a partir de otras matrices distintas a las colocadas por colonialidad/modernidad. Así, problematizamos el peligro de las imágenes naturalizadas sobre la Matemática como efecto de la colonialidad del saber. Este movimiento pretende partir de un desprendimiento epistemológico de los fundamentos de los conceptos occidentales y de la acumulación de conocimientos, para aprender a desaprender. Concluimos que asumir una actitud decolonial nos coloca en una posición de crítica continúa a todo el proceso de colonización epistémica, para que no seamos capturados por las trampas de la colonialidad/modernidad, trampas que mantienen un marco epistémico único como válido para pensar en las matemáticas, en plural.

Palabras clave: Etnomatemática; Colonialidad; Relaciones Epistémicas de Poder.

\section{Abertura}

Neste artigo $^{3}$ pretendemos trazer à discussão questões para pensar os efeitos de se assumir uma opção decolonial no campo da Educação Matemática, em particular na Etnomatemática. Essa noção tem inspiração na discussão levantada pelo filosofo latinoamericano Walter Mignolo (2008) que entende a opção decolonial quando há um caminho de desprendimentos e aberturas no campo do pensamento crítico, especialmente a partir de um desvinculamento epistêmico dos fundamentos genuínos dos conceitos ocidentais e da acumulação de conhecimento, para aprender a desaprender, para aprender junto a outros povos e comunidades nas quais, por exemplo, a distinção moderna entre teoria e prática não se aplica pois, ao contrário disso, essa distinção e outras que são próprias do pensamento europeu são sempre confrontadas.

\footnotetext{
${ }^{3}$ Este artigo é uma versão ampliada da comunicação apresentada no " $6{ }^{\circ}$ Congresso Internacional de Etnomatemática: Saberes, Diversidade e Paz" no eixo temático: Etnomatemática y lenguajes. Evento ocorrido na Universidade de Antioquia (Colômbia) em julho de 2018.
} 
A opção decolonial emerge no interior da dualidade modernidade/colonialidade como

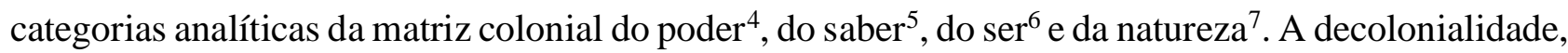
segundo Walter Mignolo, "é então uma energia que não se deixa manejar pela lógica da colonialidade e nem acredita nos contos de fadas da retórica da modernidade" (2008, p. 243), isto é, a decolonialidade como opção representa uma atitude, um movimento contínuo que tensiona e transgrede, um pensamento que se desprende e se abre para além da dualidade modernidade/colonialidade.

O desvinculamento proposto por Mignolo (2008) se inicia pelo questionamento das pretensões de objetividade do conhecimento dito científico dos últimos séculos, e nos interessa em particular pensar como a Matemática, enquanto campo disciplinar, tem participado desses movimentos. Se dissermos que as práticas da Matemática nada tiveram ou tem a ver com a história da colonialidade ${ }^{8}$ seremos facilmente desmentidos. A Matemática e os discursos a ela vinculados encobriram-se de uma falsa neutralidade, a Matemática constituiu-se como um discurso legitimador de opções político/epistemológicas que contribuíram para a legitimação e imposição da racionalidade da modernidade como padrão universal. Agora, pesquisas desenvolvidas no âmbito da Educação Matemática como as de Tamayo-Osorio (2017a; 2017b); Tamayo, Monteiro \& Mendes (2018); Oliveira \& Mendes (2018); França \& Mendes (2019), Ferreira \& Mendes (2019), assim como no âmbito da pesquisa na Educação (Indígena) como Baniwa (2011, 2019); Souza (2013); Benites (2014); Lescano (2016); Limachi, Pérez (2008); Bolaños, Mota, Tatay, Pancho (2009); Cerruto (2009); Dietz, (2008); Estrada (2008); Correa Xakriabá (2018), procuram apontar um deslocamento dessa visão universalista assim como, reivindicam uma postura distinta em relação ao conhecimento e à pesquisa, em busca de uma tessitura em torno do que Mignolo (2010) chamou de gramática da decolonialidade.

Essa gramática da decolonialidade diz a respeito a assumir a opção decolonial para tratar sobre histórias outras, vindas de escrituras e narrativas de diferentes partes do planeta, "em processo

\footnotetext{
${ }^{4}$ Quijano $(1992 ; 1997)$ desenvolveu o conceito de colonialidade do poder procurando entender as estratégias de poder subjacentes ao exercício da colonialidade, como um modelo de exercício da dominação moderna que interliga a formação racial, o controle do trabalho, o Estado e a produção de conhecimento.

${ }^{5}$ A colonialidade do saber se relaciona com a epistemologia e suas formas de reprodução de regimes de pensamento, este âmbito da colonialidade será o eixo articulador deste artigo.

${ }^{6}$ Colonialidade do ser se refere à experiência vivida de colonização e seus impactos na linguagem e na visão de mundo dos povos colonizados (MALDONADO-TORRES, 2007).

${ }^{7}$ Walsh (2017, p. 25) caracteriza a colonialidade da natureza do seguinte modo: "Hoy la colonialidad de la naturaleza representa la conjunción de la colonialidad del poder, saber y ser; es la colonialidad de la existencia-vida".

${ }^{8}$ Dizer colonialidade não é o mesmo que dizer colonialismo, segundo Grosfoguel (2008. p. 125) "não se trata de uma forma decorrente nem antecedente da modernidade. Colonialidade e modernidade constituem duas faces de uma mesma moeda. Da mesma maneira que a revolução industrial europeia foi possível graças às formas coercivas de trabalho na periferia, as novas identidades, direitos, leis e instituições da modernidade, de que são exemplo os Estado-nação, a cidadania e a democracia, formaram-se durante um processo de interação colonial e, também, de dominação/exploração, com povos não-ocidentais".
} 
afirmação de "ser de onde você pensa" (MIGNOLO, 2010, p. 96), isto é, caminhar junto a pensadores africanos e indígenas para se falar em "Novas Crônicas", o que implica um aprendizado contínuo a partir do outro, deixando-se ser afetado e desestabilizado. Estamos aqui, diante uma posição de crítica constante das possíveis armadilhas da colonialidade que buscam sempre capturar em sua lógica os que foram definidos como os "outros", inventados como diferença colonial. Assim, um pensamento decolonial se move a partir de uma crítica constante, um repensar sobre nossos modos de fazer pesquisa, em busca de modos outros de se conhecer na Educação (Matemática).

Vale a pena notar que, não há consenso quanto ao uso do conceito decolonial ou descolonial na literatura latino-americana, ambas as formas remetem à dissolução das estruturas de dominação e exploração configuradas pela colonialidade e a desconstrução de seus principais dispositivos e mecanismos de saber/poder, os quais são tensionados ao se colocar em debate outras formas de racionalidade, epistemologias outras. Walter Mignolo (2010), por exemplo, prefere referir-se à descolonialidad. Para efeitos deste artigo, nós assumimos a supressão do "s" e falamos em decolonial, não para promover um anglicismo, pelo contrário, como expressado por Walsh (2009, p. 25),

Suprimir la "s" [...] pretende marcar una distinción con el significado en castellano del "des" y lo que puede ser entendido como un simple desarmar, deshacer o revertir de lo colonial. Es decir, pasar de un momento colonial a un no colonial, como que fuera posible que sus patrones y huellas desistan en existir. Con este juego lingüístico, intento poner en evidencia que no existe un estado nulo de la colonialidad, sino posturas, posicionamientos, horizontes y proyectos de resistir, transgredir, intervenir, in-surgir, crear e incidir. Lo decolonial denota, entonces, un camino de lucha continuo en el cual se puede identificar, visibilizar y alentar "lugares" de exterioridad y construcciones alter-(n)ativas ${ }^{9}$.

Neste sentido, a intenção ao assumirmos o decolonial é provocar um posicionamento - uma postura e atitude contínua - de transgressão, intervenção e incidência sobre os problemas latinoamericanos para possibilitar novos horizontes políticos, éticos, econômicos e sociais em diálogo com a produção de conhecimento. O decolonial denota, então, um caminho de luta, de desconstrução da universalidade do pensamento moderno/colonial, pois não há outra maneira de saber, fazer e ser decolonialmente "senão mediante um compromisso com a desobediência epistêmica" (MIGNOLO, 2017, p. 23).

Pensar de modos outros significa pensar em possibilidades outras que não vão no caminho daquilo que nos leva em um movimento natural, como uma roda que nos captura e seguimos sem

\footnotetext{
9 “A exclusão do "s" [...] visa fazer uma distinção com o significado em espanhol de "des" e o que pode ser entendido como um simples desarmar, desfazer ou reverter o colonial. Ou seja, passar de um momento colonial a um não colonial, como se fosse possível que seus padrões e traços desistissem de existir. Com este jogo linguístico, procuro mostrar que não existe um estado nulo de colonialidade, mas sim posições, posicionamentos, horizontes e projetos para resistir, transgredir, intervir, emergir, criar e influenciar. O decolonial denota, então, um caminho de luta contínua em que é possível identificar, tornar visíveis e favorecer "lugares" de exterioridade e construções alternativas". [Traduação nossa].
} 
pararmos para pensar o que fazemos, o que conhecemos, pois “é a instrumentalização da razão pelo poder colonial, em primeiro lugar, que produziu paradigmas distorcidos de conhecimento e fracassou nas promessas libertadoras da modernidade. A alternativa é, portanto, clara: a destruição da colonialidade do poder mundial" (QUIJANO, 1992, p. 288).

Talvez seja necessário propor inquietações, estranhamentos, ver outras possibilidades. É nesse caminho que procuramos delinear as discussões propostas nesse texto. Fruto de nossas inquietações, geradas em nossa trajetória em processos formativos trabalhando com professores indígenas de vários povos em tempos e espaços diversos. A partir dessas experiências que tiveram suas bases iniciais orientadas por perspectivas socioculturais no âmbito da Educação Matemática, em especial na Etnomatemática, algumas perguntas sempre nos inquietaram: O que saber? Quais saberes? Qual a função desses saberes e qual o lugar da escola no cenário indígena? Talvez as melhores respostas não tenham sido aquelas que vieram responder a nossas inquietações, mas a de que não cabia a nós responder e, talvez, nem propor as perguntas nos contextos de formação de professores indígenas dos quais participamos. Foi necessário aprender com os professores indígenas e sábios das comunidades, sendo eles os principais agentes, dos lugares que transitam, para pensar e promover educações escolares indígenas baseadas em uma perspectiva de interculturalidade.

Hoje entendemos que pensar sobre interculturalidade provoca em nós, acima de tudo, a necessidade de um deslocamento de olhar, um pensar de outro modo, deixar-se ver de outros modos e deixar-se afetar por outros modos de ver o mundo. Nesse caminho é que despontou as discussões em torno da decolonialidade do poder, do saber, do ser e da natureza a partir de autoras e autores latino-americanos que propõem uma inversão do olhar de onde estamos acostumados a pensar, impregnados de uma racionalidade forjada nas relações da modernidade com a colonialidade. Alguns desses pensadores que tem nos mobilizado e acompanhado durante os últimos dez anos são Enrique Dussel, Catherine Walsh, Aníbal Quijano e Walter Mignolo a partir do que eles têm denominado giro decolonial.

Não há dúvida de que Quijano, Dussel e eu estamos reagindo, não apenas contra um imaginário histórico, mas também contra a atualidade desse imaginário hoje. Quijano tem uma perspectiva semelhante sobre a subalternização do conhecimento quando escreve: “Ao mesmo tempo em que se afirmava a dominação colonial, erigiase um complexo cultural denominada racionalidade e estabelecia-se como o paradigma universal do conhecimento e das relações hierárquicas entre a 'humanidade racional' (Europa) e o resto do mundo". (MIGNOLO, 2003, p. 93).

A opção decolonial trata de admitir a existência de padrões de poder que tem criado mecanismos e discursos para diferenciar hierarquicamente grupos sociais, práticas e costumes, formas de pensar; assim como, a necessidade de enfrentamento dos pilares estruturais de discursos e lógicas que privilegiam um único modelo epistemológico. Significa pensar uma Educação Matemática, ou 
uma Etnomatemática, que questiona a si mesma e, além do mais que se contrapõe às práticas racistas e ao projeto eurocêntrico de saber que inferioriza e discrimina todos os saberes que não se submetem à matriz cultural branca europeia, no caso a Matemática - disciplinarmente organizada -e seus padrões.

Vemos que estas ideias propõem assumir uma postura decolonial ao promover um processo de desnaturalização das matrizes e formas de pensar calcadas na colonialidade do saber e do poder (MIGNOLO 2005; LANDER, 2005), que ao longo de toda a modernidade foram se estabelecendo mediante uma soberania em relação à forma como se pensava e se produzia conhecimento. Essa soberania foi pautada em modelos epistemológicos hegemônicos dentro da ciência moderna, de forma a subalternizar as formas desviantes daquela Institucionalizada, impedindo sua emergência ou cerceando seu desenvolvimento.

Como diz Mignolo (2005), lançar um olhar para as formas semióticas e paralelas que ocorrem nas margens, nas bordas das estruturas políticas e econômicas, com o objetivo de saber que há outros mundos possíveis. Esse autor propõe a necessidade de pensar além das categorias promovidas pelas línguas associadas ao grego e latim que formaram as 6 línguas imperiais da modernidade/colonialidade (espanhol, português, francês, italiano, inglês, alemão). É necessário desprender-se das forças de categorias de pensamento que naturalizam a colonialidade, calcadas na retórica de desenvolvimento e do progresso. É necessário pensar nas fronteiras, a partir da diferença colonial, a qual Mignolo (2005) entende como sendo um giro que surge da diferença, ou seja, de tudo aquilo que o pensamento único em sua ótica de colonialidade reduziu ao silêncio, ao passado, à tradição, ao demônio, ao superado, ao não sustentável e mais fortemente ao não existente.

Assim, nos propomos trazer esse pensamento decolonial para pensar questões no campo da Educação Matemática, em particular na Etnomatemática, ao problematizar imagens naturalizadas sobre a Matemática que na escola se processa como efeito da colonialidade do saber, sendo esse o elemento no qual centraremos nosso olhar, sem desconhecer que esta forma de colonialidade se imbrica e opera junto com outras (CASTIANO, 2010; TAMAYO-OSORIO, 2016, 2017; OLIVEIRA \& MENDES; 2018; FRANÇA \& MENDES, 2019; FERREIRA \& MENDES, 2019).

\section{Colonialidade do saber: uma narrativa universal da modernidade}

Falar da colonialidade do saber propõe ir além do legado das desigualdades e injustiças sociais, é necessário pensar que há um legado epistemológico, como afirma Segrera (2005) que impede a compreensão do mundo a partir dele próprio e das epistemes que lhe são próprias. Ao mesmo 
tempo, pensar sobre que, efeito do pensamento moderno ocorreu uma dominação epistêmica com base na hegemonia da concepção de conhecimento do europeu. Este totalitarismo epistêmico,

ou tal dieta unilateral de uma imagem de conhecimento, negou e, nega ainda, outras formas de conhecer diferentes daquelas em conformidade a tal concepção hegemônica de conhecimento, que permeia diversos campos disciplinarmente organizados, tanto nas universidades, quanto nos sistemas de escolarização modernos, dentre os que encontramos a Matemática. Esta racionalidade, ancorada ao paradigma da modernidade e da colonialidade do saber, "estabeleceu, não só, ao eurocentrismo como perspectiva única de conhecimento, mas também, ao mesmo tempo, descartou por completo a produção intelectual indígena e afro como "conhecimento" e, consequentemente, sua capacidade intelectual" (TAMAYOOSORIO, 2017b, p. 46).

Como isso operou pode ser entendido a partir do caminho proposto por Lander (2005) ao apresentar um percurso na compreensão da colonialidade do saber e do poder com base na relação entre modernidade e colonialidade. As bases da formação do pensamento moderno, para esse autor, desenvolveram-se a partir da lógica da expansão colonial, estando ambos intrinsicamente ligados. Para isso, o autor aponta que a eficácia do pensamento científico moderno deu-se a partir da naturalização das relações sociais, fundado em uma narrativa histórica que se assenta no conhecimento objetivo, científico e universal. Sendo as relações coloniais/imperiais as articuladoras dos saberes modernos com a organização do poder.

Os modos de produção dessas ordens de saberes deram-se a partir de fragmentações, separações que foram desenvolvidas no Ocidente. Uma primeira religiosa, na separação entre Deus, homem e natureza, em que o homem assumiria uma centralidade no controle da natureza e depois na divisão entre mente e corpo, razão e mundo. O mundo e o corpo ficaram vazios de significado relegando uma centralidade radical à mente/razão. Assim o mundo passa a ser visto como um mecanismo desespiritualizado, que pode ser captado pelos conceitos e representações construídas pela razão, gerando uma forma de conhecimento descorporificado e descontextualizado. De tal modo, a colonialidade instaura sua força na associação no âmbito do poder o campo do saber, construindo a colonialidade do saber que age de forma para a manutenção de uma hegemonia eurocêntrica como perspectiva superior de conhecimento.

Entretanto, continua Lander, essas sucessivas divisões sempre se articulam a partir de um contraste, o qual, na conformação colonial do mundo, propôs uma divisão entre ocidente ou europeu (signo do moderno e avançado) e os "outros" (restante dos outros povos e culturas do planeta).

Nesse cenário, a América (o Novo mundo) cumpre o papel de afirmar a centralidade mundial da Europa moderna. Ela aparece não apenas na organização colonial do mundo, mas na constituição colonial dos saberes, das linguagens e das memórias (MIGNOLO apud LANDER, 2005) e do imaginário (QUIJANO apud LANDER, 2005), a partir de processos que organizam a totalidade do 
espaço e do tempo colocando todos em narrativa universal. Produz-se um lugar privilegiado de enunciação (discurso de poder imperial), universal, que produz a divisão: Europa/Ocidente e o “outro", o europeu e o "índio".

Uma universalidade que tem como efeito um processo radicalmente excludente. Nas palavras de Boaventura Santos (2007), um acúmulo de experiências desperdiçadas e a promoção de um epistemicídio de diversas formas de conhecer não conformadas ao mundo moderno.

A construção dessa universalidade foi necessária para estabelecer uma conformação colonial do mundo, construir uma narrativa universal em articulação com aquilo que contrasta, ou seja, coloca de um lado o ocidente ou o mundo europeu e do outro lado o restante dos povos e culturas do planeta. Para a construção dessa narrativa de universalidade foi necessário colocar a América, em particular, não apenas em uma organização política colonial de mundo, mas houve um investimento na constituição colonial dos saberes, das linguagens e das memórias bem como da organização de uma totalidade do espaço e do tempo.

Esse processo de exclusão, como pontua Lander ao retomar Clavero (1994 apud LANDER, 2005), nega qualquer forma de direito que não esteja dentro da racionalidade do liberalismo, ou seja o direito do indivíduo sobre a natureza só existe se ela é por ele ocupada para o trabalho e a produção, ancorada em uma narrativa de progresso. Tal racionalidade entra em conflito com outras formas de pensar a relação com a natureza, como por exemplo dos grupos indígenas ameríndios: "se não há cultivo ou colheita... outros usos não valem ... o indígena que não se atenta a esses conceitos, a tal cultura, não têm nenhum direito" (p.22). Surge daí o discurso do proprietário, só o é quem toma posse com o princípio de produção.

Nessa grande narrativa surgem a visão universal de história associada ao progresso, as classificações e hierarquizações de todos dos povos e experiências históricas, a naturalização das relações sociais, a promoção da superioridade dos conhecimentos produzidos pela sociedade moderna liberal/capitalista e a criação de categorias universais de análise. Gerando um dispositivo colonizador do conhecimento que estabelece formas "normais" do ser humano e da sociedade. Assim todas as outras formas de ser, organizações sociais e formas de conhecimento outras são transformadas não apenas em diferentes, mas são categorizadas segundo uma ótica colonial/moderna em carentes, arcaicas, primitivas, tradicionais, pré-modernas. São colocadas em um momento anterior de desenvolvimento histórico da humanidade, as quais, no imaginário do progresso, são postas no patamar da inferioridade. Criam-se os outros/as, impossibilitados de "se superarem" e de chegarem a ser modernos (LANDER, 2005). 


\section{Decolonizar o saber na Educação Matemática e na Etnomatemática: mover-se por outras experiências negadas pela modernidade/colonialidade}

Lizcano (2006), particularmente no campo da Matemática, traz à discussão a questão da colonialidade do saber com a seguinte afirmação: "el etnocentrismo de nuestra tribu se mira el ombligo, por así decirlo, científica y racionalmente. El etnocentrismo de nuestra tribu es etnófugo, criptoétnico, epistemocéntrico"10 (LIZCANO, 2006, p. 12). Na visão desse autor a visão de colonialidade do saber pode ser representada pela manutenção do conhecimento Matemático da “tribo europeia", nas palavras de Lizcano (2006), como padrão universal, único e neutro e sua articulação aos mecanismos do projeto modernidade/colonialidade. Nesse sentido, o eurocentrismo é colocado como um lócus epistêmico de onde se constrói um modelo de conhecimento que, como efeito, provoca a falsa percepção de universalização das experiências e formas de vida europeia como modelo normativo a ser seguido, determinando como únicos e válidos os conhecimentos que 'pertencem' a essa “tribo”. Indo além, o autor reforça que:

Si nuestra geometría es imaginaria (e ideológica), nuestro imaginario y nuestra ideología son geométricos. Lo malo no es la universalidad de la ciencia sino la de las creencias; lo malo no es la objetividad de la ciencia sino la "cientificación" de la subjetividad. Cuando liberemos los ángulos y las hipotenusas, prisioneras de los cálculos del Pentágono, aún habrá que reprimirlas para que no nos escamotean la ondulación; es decir, la independencia ontológica de las montañas, los cuerpos y las casas $^{11}$. (LIZCANO, 2006, p. 19).

A partir de Lizcano (2006) podemos ver uma narrativa de universalidade vinculada com a Matemática que ainda toma conta do mundo contemporâneo e dos cenários escolares, marcada fortemente pelos processos de escolarização moderna, bem como de pesquisas que usam como padrão de correção das práticas culturais a Matemática da 'tribo europeia'. Buscar entender as tramas que compõem tal narrativa configura-se em um movimento de um pensamento decolonial e, como aponta Tamayo-Osorio (2017a, p. 175), “decolonizar este projeto intelectual/civilizatório de caráter disciplinar e de inspiração metafísica implica não só compreender a palavra, as linguagens, em suas diferentes manifestações performáticas e performativas, mas também uma revolução "em pensamento", "no pensamento", uma decolonização do pensamento".

Nessa narrativa de universalidade, os discursos sobre a independência da Matemática em relação à língua advogam uma universalidade nos modos de fazer Matemática, a partir de seu

\footnotetext{
10 "o etnocentrismo de nossa tribo é olhar para o umbigo, por assim dizer, científica e racionalmente. O etnocentrismo de nossa tribo é etnofóbico, cripto-étnico, epistemocêntrico". [tradução nossa].

11 “Se nossa geometria é imaginária (e ideológica), nosso imaginário e nossa ideologia são geométricas. O ruim não é a universalidade da ciência, mas das crenças; o ruim não é a objetividade da ciência, mas a "cientificação" da subjetividade. Quando liberarmos os ângulos e as hipotenusas, prisioneiros dos cálculos do Pentágono, ainda teremos que reprimi-los para que não nos desapaream a ondulação; ou seja, a independência ontológica de montanhas, corpos e casas". [tradução nossa].
} 
formalismo e rigor simbólico, conferindo um status de universalidade ao conhecimento Matemático, pois,

O uso da Matemática, a partir de Galileu e Newton, como instrumento privilegiado de análise e fundamento da lógica investigativa da ciência moderna, traz duas consequências principais: em primeiro lugar, a ideia de que conhecer significa quantificar e que, por tanto o que não é quantificável é cientificamente irrelevante. Em segundo lugar, o método científico assenta na redução da complexidade na medida em que entende que conhecer significa dividir e classificar para depois poder determinar relações sistemáticas entre o que se separou (p.15). Ou seja, diz Boaventura, é um conhecimento causal que aspira à formulação de leis, à luz de regularidades observadas, com vista a prever o comportamento futuro dos fenômenos (p.16) [...]. (OLIVEIRA, 2008, p.19).

Desse modo, vale a pena levantar questões sem que haja uma busca por respostas conclusivas, mas que tenham a potência de provocar inquietações em torno dessa ideia de decolonização do pensamento e do saber: quais movimentos são possíveis de um pensamento decolonial na narrativa universal sobre a Matemática e que implicações teriam no campo da Educação Matemática?

Monteiro \& Mendes (2015, p. 5), ao discutir a Etnomatemática como um movimento de contra-conduta no interior da Matemática e da Educação Matemática, destacam o discurso gerado por esse campo que questiona narrativas de universalização do conhecimento matemático, bem como a eficácia dessas narrativas em promover uma verdade única e referencial para dizer o que pode ser considerado como conhecimento. As autoras acrescentam que o movimento faz emergir uma outra formação discursiva que se apresenta como forma de resistência aos modos de governamento (im)postos pelo campo da Matemática formal, "uma resistência que não nega a matemática, tão pouco pretende instituir uma revolução nesse campo do saber, mas busca novas formas de pensar esse saber, novas condutas e normas de constituição desse saber, por isso estamos aqui entendendo-a como um movimento de contra-conduta". Nesse sentido, se entendermos a Etnomatemática como movimento de contra-conduta, nasce um questionamento sobre como decolonizar imagens de uma Matemática única e universal no desenvolvimento de pesquisas que pretendam percorrer modos outros de conhecer e que mobilizem condutas outras em torno desses conhecimentos?

O movimento de decolonização do pensamento e do saber é possível quando damos atenção a outras formas de se desenhar o que se entende por conhecimento a partir de outras matrizes que não as colocadas pela modernidade/ colonialidade. Lizcano (2006), no seu estudo sobre os conhecimentos do que ele denomina "matemática taoista" da época imperial dos primeiros Han (século II. a. C), elabora alguns questionamentos em torno do que ele tinha estudado durante a vida partindo de um livro Zhuang zi. Entendemos que essas questões deveriam ser foco de pesquisas que assumem uma opção decolonial:

¿Todas las matemáticas son iguales y por lo tanto las occidentales son también "chinas", son también un "cuento chino"? ¿Son las dos igualmente irracionales, 
imaginarias y por lo tanto igualmente instrumentos imperialistas de conquista? ¿O las matemáticas chinas son "superiores" y no porque sean más racionales sino precisamente porque son más imaginarias o, más exactamente, porque el imaginario chino, allí donde la razón es siempre imaginaria, es superior al griego? ¿Con qué criterio comparamos axiológicamente dos imaginarios sociales diferentes? ¿Es la clase o la tribu la que configura un imaginario dominante? ¿La clase burguesa sólo produce burguesía? ¿El lenguaje sólo transporta metáforas? ¿La historia sólo genera más historia como las hormigas sólo generan más hormigas? ${ }^{12}$ (LIZCANO, 2006, p. 23).

Vale a pena trazer a discussão apresentada por Castiano (2010), professor da Universidade Eduardo Mondlane em Maputo, Moçambique, ao tratar de referenciais para pensar a filosofia africana. Para fazer esse caminho o autor apresenta críticas que foram tecidas por autores africanos a diversos estudos no campo das etnociências e etnofilosofia. Tais críticas apontam que ditos estudos muitas vezes acabaram por realizar processos de objetivação das culturas e conhecimentos locais a partir de referenciais calcados em modelos epistêmicos ocidentais. Tais críticas ressaltam que "inscrever nas ciências naturais positivas o conhecimento local existente e em uso pelas diferentes comunidades, ocorre com deturpações claras de método científico e de objecto de análise" (CASTIANO, 2010, p. 18).

A posição de Castiano aponta que tais críticas questionam o real papel das etnociências e acrescenta qual seria "o real objectivo ao tentar descortinar os conhecimentos, julgados latentes pelos etnocientistas, existentes nas comunidades." (CASTIANO, 2010, p. 18). O autor considera relevantes tais críticas, e coloca sua posição ao ressaltar a necessidade, para que haja uma real contribuição dos estudos nesses campos para a celebração de ciências africanas, da criação de espaços em que se possa interagir com os saberes locais a partir referenciais epistêmicos novos. Ao falar sobre ciências africanas Castiano reforça a necessidade de "cultivar uma abertura epistemológica suficiente para, a partir dos quadros epistémicos sugeridos pelos sábios das diversas culturas, modificar os seus próprios pressupostos teóricos.” (CASTIANO, 2010, p. 50).

É importante reconhecer que, no interior da Educação Matemática, a emergência da Etnomatemática representa um campo potente para provocar um pensamento decolonial. Isso porque, podemos dizer que os movimentos de pesquisa sobre os saberes no interior de distintas práticas culturais alinhados ao Programa de Pesquisa da Etnomatemática, proposto por Ubiratan D’Ambrosio, abriram portas para possibilidades e saberes e pensamentos outros.

\footnotetext{
12 "Todas as matemáticas são iguais e, portanto, a matemática ocidental também é "chinesa", é também um "conto chinês"? As duas são igualmente irracionais, imaginárias e, portanto, instrumentos de conquista igualmente imperialistas? Ou a matemática chinesa é "superior" e não porque seja mais racional, mas precisamente porque é mais imaginária ou, mais exatamente, porque o imaginário chinês, ali onde a razão é sempre imaginária, é superior ao grego? Com quais critérios comparamos axiologicamente dois imaginários sociais diferentes? É a classe ou a tribo que configura um imaginário dominante? A classe burguesa só produz burguesia? A linguagem carrega apenas metáforas? A história apenas gera mais história como as formigas geram apenas mais formigas?’. [tradução nossa].
} 
Desse modo, mover-se por uma opção decolonial no interior das pesquisas desenvolvidas no campo da Etnomatemática demanda, como o professor D’Ambrósio (2016) coloca, sair das gaiolas epistemológicas que são base do pensamento moderno/colonial, significa entrar em outros quadros epistêmicos como propõem Castiano (2010) e Lizcano (2009), ou seja, buscar modos outros de conhecer a partir de suas próprias referências epistemológicas. Assim, assumir uma atitude decolonial nos coloca numa posição de crítica continua a todo processo de colonização epistêmica, para que não sejamos capturados pelas armadilhas da colonialidade/modernidade, armadilhas que mantém um único referencial epistêmico como válido para pensar as matemáticas, no plural.

\section{Referências}

CASTIANO, José. P. Referenciais da Filosofia Africana: Em Busca da Intersubjectivação. Maputo -Moçambique: Sociedade Editorial Ndjira, 2010.

BANIWA, Gersem. Educação para manejo e domesticação do mundo: entre a escola ideal e a escola real Os dilemas da educação escolar indígena no Alto Rio Negro, tese de doutorado, Universidade de Brasília, UNB, 2011.

BANIWA, Gersem. Educação Escolar Indígena no século XXI: encantos e desencantos. Rio de Janeiro: Morula/LACED, 2019.

BENITES, Eliel. Oguata pyahu (uma nova caminhada) no processo de desconstrução e construção da educação escolar indígena da reserva indígena Te’ýikue. Dissertação (mestrado em educação) - UCDB, Campo Grande, 2014.

BOLAÑOS, Graciela; TATAY, Libia; PANCHO, Avelina. Universidad Autónoma, Indígena e Intercultural: Un proceso para fortalecer la educación propia y comunitaria en el marco de la interculturalidad. In: D. Mato (coord.). Instituciones Interculturales de Educación Superior en América Latina. Procesos de construcción, logros, innovaciones y desafíos. Caracas: UNESCOIESALC. 2009.

CERRUTO, Leonel. La experiencia de la Universidad Indígena Intercultural Kawsay. In: D. Mato (coord.). Instituciones Interculturales de Educación Superior en América Latina. Procesos de Construcción, Logros, Innovaciones y Desafíos. Caracas: UNESCO-IESALC. pp. 123-154. 2009.

CORREA XAKRIABÁ, Célia Nunes. O Barro, o Genipapo e o Giz no fazer epistemológico de Autoria Xakriabá: reativação da memória por uma educação territorializada. Dissertação de Mestrado - Centro de Desenvolvimento Sustentável, Universidade de Brasília. Mestrado Profissional em Sustentabilidade junto a Povos e Terras Tradicionais (MESPT). 2018.

D’AMBROSIO, Ubiratan. A Metáfora das Gaiolas Epistemológicas e uma Proposta Educacional. Perspectivas da Educação Matemática, v. 9, n. 20, 27 dez. 2016.

DIETZ, Gunther. La experiencia de la Universidad Veracruzana Intercultural. In: D. Mato (coord.). Diversidad Cultural e Interculturalidad en Educación Superior. Experiencias en América Latina. Caracas: UNESCO-IESALC. 2008. 
ESTRADA, Guillermo. Sobre la experiencia del Centro de Estudios Ayuuk - Universidad Indígena Intercultural Ayuuk. In: D. Mato (coord.). Diversidad Cultural e Interculturalidad en Educación Superior. Experiencias en América Latina. Caracas: UNESCO-IESALC. pp. 371-381. 2008.

FERREIRA, Marta; MENDES, JAckeline. Saberes Afrodiaspóricos: SULear olhares, trançar sentidos. Revista Interdisciplinar Sulear, v. 2, p. 156-162, 2019.

FRANÇA, Evanílson; MENDES, Jackeline. Nós, os de lá, estamos cá: reflexões sobre a educação escolar quilombola no contexto dos impedimentos à co-presença. Horizontes, v. 37, p. 1-20, 2019.

GROSFOGUEL, Ramón. Para descolonizar os estudos de economia política e os estudos póscoloniais: Transmodernidade, pensamento de fronteira e colonialidade global. Revista Crítica de Ciências Sociais, n. 80: mar. 2008.

LANDER, Emanuel. Ciências sociais: saberes coloniais e eurocêntricos, in Edgardo Lander (org). A colonialidade do saber: eurocentrismo e ciências sociais. Perspectivas latinoamericanas. Colección Sur Sur, CLACSO, Ciudad Autónoma de Buenos Aires, Argentina. Setembro, 2005.

LESCANO, Claudemir. P. Tavyterã Reko Rokyta: os pilares da educação Guarani Kaiowá nos processos próprios de ensino e aprendizagem. Dissertação (mestrado em educação) Universidade Católica Dom Bosco, Campo Grande, 2016.

LIMACHI PÉREZ, Vicente. La experiencia del Programa de Formación en Educación Intercultural Bilingüe para los Países Andinos (PROEIB-Andes), sede Universidad Mayor de San Simón, Bolivia. In: D. Mato (coord.). Diversidad Cultural e Interculturalidad en Educación Superior. Experiencias en América Latina. Caracas: UNESCO-IESALC. pp. 439-448. 2008.

LIZCANO, E. Metáforas que nos piensan: sobre ciencia, democracia y otras poderosas ficciones. Madrid: Traficantes de Sueños. 2006.

MALDONADO-TORRES, Nelson. Sobre la colonialidad del ser, contribuciones al desarrollo de un concepto. In: CASTRO-GOMEZ, Santiago; GOSFROGUEL, Ramón (Comp). El giro decolonial: reflexiones para una diversidad epistémica más allá del capitalismo global. Bogotá:

Universidad Javeriana-Instituto Pensar, Universidad Central-IESCO, Siglo del Hombre, 2007. p. 127-167.

MIGNOLO, Walter D. Histórias locais/Projetos globais. Colonialidade, saberes subalternos e pensamento liminar. Belo Horizonte: UFMG, 2003.

MIGNOLO, Walter D. A colonialidade de cabo a rabo: o hemisfério ocidental no horizonte conceitual da Modernidade. In: E. Lander (org.) Colonialidade do saber: eurocentrismo e Ciências Sociais. Perspectivas latinoamericanas, Colección Sur Sur, CLACSO, Ciudad Autónoma de Buenos Aires, Argentina. Setembro, 2005.

MIGNOLO, Walter. Desafios decoloniais hoje. Em Epistemologias do sul. FOZ DO IGUAÇU/PR, 1 (1), PP. 12-32, 2017.

MIGNOLO, W. La opción de-colonial: desprendimiento y apertura. Un manifiesto y un caso. Tabula Rasa, Bogotá - Colombia, No.8: 243-281, janeiro-junho 2008. 
MIGNOLO, Walter. Desobediencia epistémica: retórica de la modernidad, lógica de la colonialidad y gramática de la descolonialidad. Buenos Aires: Ediciones del Signo, 2010.

MOTA, João da Conceição Ferreira. A escola indígena Xakriabá: suas histórias e seu crescimento. 2013. Trabalho de Conclusão de Curso (Licenciatura)-Faculdade de Educação, Universidade Federal de Minas Gerais, Belo Horizonte, 2013. Habilitação em Ciências Sociais e Humanidades.

MONTEIRO, Alexandrina; MENDES, Jackeline R. Etnomatemática como Movimento de Contraconduta na Mobilização de Saberes em Práticas Culturais. Disponível nos anais do SIMPÓSIO INTERNACIONAL DE PESQUISA EM EDUCAÇÃO MATEMÁTICA, 6. Recife. Pirenópolis, 2015, p.1-11.

OLIVEIRA, Inês. Boaventura \& a Educação. (2. ed.). Belo Horizonte: Autêntica, 2008.

OLIVEIRA, Maria Aparecida M.; MENDES, Jackeline R. Formação de professores Guarani e Kaiowá: interculturalidade e decolonialidade no ensino de matemática. ZETETIKÉ (on line), v. 26, p. 167-184, 2018.

QUIJANO, Anibal. Colonialidad y modernidad-racionalidad. In: Heraclio Bonilla. (Org.), Los conquistados. 1492 y la poblaciones indígenas de las Américas. Quito: Tercer Mundo. 1992.

QUIJANO, Aníbal. Colonialidad del Poder, Cultura y Conocimiento en América Latina. In: Anuário Mariateguiano. Lima: Amatua, v. 9, n. 9.1997

SANTOS, Boaventura. Para Além do pensamento abissal. Novos estudos, 79 (2), nov. 2007.

SEGRERA, Francisco L. Apresentação. In: E. Lander (org.) Colonialidade do saber: eurocentrismo e Ciências Sociais. Perspectivas latinoamericanas, Colección Sur Sur, CLACSO, Ciudad Autónoma de Buenos Aires, Argentina. Setembro, 2005. (p.33-49).

SOUZA, T. de. Educação Escolar Indígena e as políticas públicas no município de Dourados/MS. Dissertação (mestrado em educação) - Universidade Católica Dom Bosco, Campo Grande, 2013.

TAMAYO-OSORIO, Carolina. Vení, vamos hamacar el mundo, hasta que te asustes: uma terapia do desejo de escolarização moderna. (Tese de doutorado). Universidade Estadual de Campinas, São Paulo. 2017a.

TAMAYO-OSORIO, Carolina. A colonialidade do saber: Um olhar desde a Educação Matemática. Revista Latinoamericana de Etnomatemática, 10(3), 39-58, 2017b.

TAMAYO, Carolina; MONTEIRO, Alexandrina; MENDES, Jackeline. Caminhos investigativos nas relações entre Educação (matemática), Linguagem e Práticas Culturais. Em Ensino Em ReVista, Uberlândia, v.25, n.3, p.588-60, set./dez./2018.

WALSH, Catherine. Interculturalidad crítica y educación intercultural. 2009. Conferência apresentada no Seminário "Interculturalidad y Educación Intercultural", Instituto Internacional de Integración del Convenio Andrés Bello, La Paz). Disponível em: <http://docplayer.es/13551165Interculturalidad-critica-y-educacion-intercultural.html>. 
WALSH, Catherine. ¿Interculturalidad y (de)colonialidad? Gritos, grietas y siembras desde AbyaYala. In: DINIZ, Alai Garcia; PEREIRA, Diana Araujo; ALVES, Lourdes Kaminski (Org.). Poéticas e políticas da linguagem em vias de descoloniazação. São Carlos: Pedro \& João Editores, 2017. 